\title{
Ultrasound Microbubble Contrast Agents for Diagnostic and Therapeutic Applications: Current Status and Future Design
}

\author{
Shih-Tsung Kang, PhDc; Chih-Kuang Yeh, PhD
}

\begin{abstract}
Ultrasound contrast agents are highly echogenic microbubbles with many unique properties. Microbubbles can basically improve the sensitivity of conventional ultrasound imaging to the microcirculation. The resonance of microbubbles in response to an incident ultrasound pulse results in nonlinear harmonic emission that serves as the signature of microbubbles in microbubble-specific imaging. Inertial cavitation and destruction of microbubbles can produce a strong mechanical stress enhancing the permeability of the surrounding tissues, and can further increase the extravasation of drugs from the blood into the cytoplasm or interstitium. Stable cavitation by high-frequency ultrasound can also mildly increase tissue permeability without causing any damage even at a high acoustic pressure. Microbubbles can carry drugs, release them

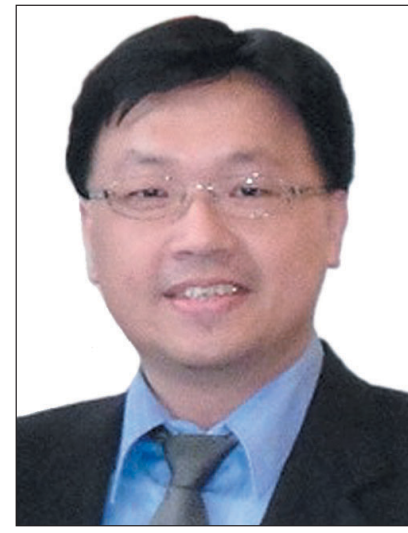

Prof. Chih-Kuang Yeh upon ultrasound-mediated microbubble destruction, and simultaneously enhance vascular permeability to increase drug deposition in tissues. Various targeting ligands can be conjugated to the surface of microbubbles to attain ligand-directed and site-specific accumulation for targeted imaging. In addition to current developments in microbubble technology, this review introduces our studies of the applications of microbubble-specific imaging, ultrasound-aided drug delivery, and targeted imaging. These applications are promising but may require further improvement for clinical use. (Chang Gung Med $J$ 2012;35:125-39)
\end{abstract}

Key words: microbubbles, contrast imaging, molecular imaging, targeted therapy, controlled drug release, cavitation

$\mathrm{U}^{\prime}$ Itrasound imaging has been one of the most popular medical diagnostic techniques because of its superior safety, low cost, and easy accessibility compared with other imaging modalities such as computed tomography, positron emission tomography, and magnetic resonance imaging (MRI). Ultrasound imaging can provide real-time quantita- tive information on the morphology and perfusion of biological tissues for evaluation of a variety of diseases in cardiology, radiology, and oncology. ${ }^{(1-5)}$ In recent years, much attention has focused on observation of the microcirculation in the different types of diseases or abnormalities in tissues. For example, the dependence of angiogenesis on tumor growth and

From the Department of Biomedical Engineering and Environmental Sciences, National Tsing Hua University, Hsinchu, Taiwan. Received: Sep. 8, 2011; Accepted: Nov. 30, 2011

Correspondence to: Prof. Chih-Kuang Yeh, Department of Biomedical Engineering and Environmental Sciences, National Tsing Hua University, Hsinchu, Taiwan. 101, Section 2, Kuang-Fu Road, Hsinchu 30013, Taiwan (R.O.C.)

Tel: 886-3-5715131 ext. 34240; Fax: 886-3-5718649; E-mail: ckyeh@mx.nthu.edu.tw 
progression has highlighted the importance of noninvasive visualization of the tumor microvasculature to determine treatment strategies and assess therapeutic efficacies. ${ }^{(6-9)}$ However, the sensitivity and specificity of ultrasound diagnoses are susceptible to low contrast differences between blood and tissue. Conventional ultrasound Doppler imaging only permits flow assessment of vessels larger than hundreds of micrometers, such as arterioles and venules. These limitations have recently been overcome by the development of ultrasound contrast agents (UCAs).

The first use of UCAs was reported in echocardiography by Gramiak and Shah in 1968. ${ }^{(10)}$ These UCAs were room air bubbles with no protective shell, so they disappeared within a few seconds after intravenous administration. Currently-used UCAs are more stable microbubbles composed of low-diffusivity gases such as nitrogen or perfluorocarbon stabilized by a coating of biodegradable material such as albumin, phospholipids, or polymers. ${ }^{(11)}$ Phospholipids are commonly used since lipid-coated microbubbles are easier to fabricate and are much more echogenic than those made of other materials. ${ }^{(12)}$ Microbubbles are highly echogenic in vivo because of a mismatch in acoustic impedances (i.e., the product of density and the speed of sound) between their gas cores and surrounding tissues. Once administered into a body cavity or the cardiovascular system, microbubbles are capable of increasing the intensity of backscattered ultrasound to up to $20-30 \mathrm{~dB}$. ${ }^{(13)}$ The contrast enhancement can clarify delineation of the borders of body cavities (e.g., the left ventricular cavity) and increase the Doppler signals from intracranial vessels. ${ }^{(14-16)}$ The improved sensitivity of ultrasound to microcirculation assists in characterization of possible lesions in the liver and assessment of the vascular phenotype of a tumor. ${ }^{(17-19)}$ Several researchers have also reported the successful use of microbubbles in preclinical diagnoses of cardiovascular and renal diseases. ${ }^{(20-23)}$

In addition to contrast enhancing ability, microbubbles possess unique properties that can be exploited to improve both diagnoses and therapies. Taking advantage of these properties could lead to emerging applications such as microbubble-specific detection and ultrasound-controlled targeted drug delivery. These applications are promising for further improvement in ultrasound imaging of the microcirculation and treatment in the imaged regions. In this article, we review current developments in microbubble technology and efforts by our laboratory to realize these emerging applications.

\section{Commercial and homemade microbubbles}

At present, 3 commercial agents, Optison ${ }^{\mathrm{TM}}(\mathrm{GE}$ Healthcare, Milwaukee, WI, U.S.A.), Definity ${ }^{\circledR}$ (Lantheus Medical Imaging, Billerica, MA, U.S.A.), and SonoVue ${ }^{\circledast}$ (Bracco SpA, Milano, Italy) are licensed for cardiology applications. Optison ${ }^{\mathrm{TM}}$ and Definity ${ }^{\circledast}$ are available in both the United States and the European Union, whereas SonoVue ${ }^{\circledast}$ is only available in the European Union. Detailed information on these agents is available in the Table. ${ }^{(11,24-26)}$

Table Specifications of Commercial and Homemade Microbubbles

\begin{tabular}{|c|c|c|c|c|c|c|c|}
\hline Name & Manufacturer & $\begin{array}{c}\text { Shell } \\
\text { material }\end{array}$ & Gas & $\begin{array}{l}\text { Mean size } \\
\quad(\mu \mathrm{m})\end{array}$ & $\begin{array}{l}\text { Percentage } \\
\text { less than } \\
10 \mu \mathrm{m}\end{array}$ & $\begin{array}{l}\text { Concentration } \\
\text { (bubbles/mL) }\end{array}$ & $\begin{array}{l}\text { Imaging } \\
\text { time } \\
\text { (minutes) }\end{array}$ \\
\hline Optison $^{\mathrm{TM}}$ & GE Healthcare & Albumin & $\mathrm{C}_{3} \mathrm{~F}_{8}$ & $2.0-4.5$ & $95 \%$ & $5.0-8.0 \times 108$ & $2.5-4.5$ \\
\hline $\begin{array}{l}\text { Definity }^{\circledR} \\
\text { (Luminity }^{\circledR} \text { in the } \\
\text { European Union) }\end{array}$ & $\begin{array}{l}\text { Lantheus } \\
\text { Medical } \\
\text { Imaging }\end{array}$ & Phospholipid & $\mathrm{C}_{3} \mathrm{~F}_{8}$ & $1.1-3.3$ & $98 \%$ & $1.2 \times 10^{10}$ & $2-10$ \\
\hline SonoVue ${ }^{\circledast}$ & Bracco SpA & Phospholipid & $\mathrm{SF}_{6}$ & $2-8$ & $99 \%(<11 \mu \mathrm{m})$ & $0.9-6 \times 10^{9}$ & $3-6$ \\
\hline $\begin{array}{l}\text { Homemade } \\
\text { Microbubbles }\end{array}$ & $\begin{array}{c}\text { Yeh Group } \\
\text { at National } \\
\text { Tsing Hua University }\end{array}$ & $\begin{array}{l}\text { Phospholipid/ } \\
\text { Lipopolymer }\end{array}$ & $\mathrm{C}_{3} \mathrm{~F}_{8}$ & $0.2-0.7$ & $>99.9 \%$ & $1.4-3.0 \times 1010$ & $10-20$ \\
\hline
\end{tabular}


The microbubbles in these agents are larger than $1 \mu \mathrm{m}$ with useful imaging durations of less than 10 $\min$.

Our previous studies have demonstrated the fabrication of homemade microbubbles in the submicron scale, as shown in Fig. 1A. ${ }^{(27,28)}$ These microbubbles are composed of perfluoropropane gas and phospholipids prepared in phosphate buffered saline with mean sizes of about $200-700 \mathrm{~nm}$, as shown in Fig. 1B, which are much smaller than those in commercial agents (refer to the Table for comparisons). The concentrations within $0.8-7 \mu \mathrm{m}$ are about $1-5 \mathrm{x}$ $10^{10}$ bubbles $/ \mathrm{mL}$ with less than $0.1 \%$ of the whole population larger than $10 \mu \mathrm{m}$. The small size distribution prevents the microbubbles from being entrapped in the pulmonary capillary bed, thereby permitting a long imaging duration of up to $20 \mathrm{~min}$ in vivo; the imaging duration of SonoVue ${ }^{\circledast}$ is less than 6 min. ${ }^{(29,30)}$ Note that phospholipids are commonly used in the formulation and manufacturing of liposomes, a drug delivery system currently approved by the United States Food and Drug Administration (FDA). Perfluoropropane gas is chemically inert and does not generate toxicity during metastasis. Hence, homemade microbubbles are biologically safe and biocompatible, and do not cause a severe immune response in the the host. They can ultimately be cleaned through the immune and respiration systems. ${ }^{(31,32)}$

\section{Nonlinear properties of microbubbles}

Unlike rigid particles, microbubbles are highly compressible, and are able to oscillate, i.e., repeatedly expand and contract in response to the pressure changes of an ultrasound pulse. The wall velocity is achieved in the order of tens to hundreds of meters per second, as demonstrated by high-speed photography. ${ }^{(33)}$ When driven at acoustic pressures as low as tens of kilopascals, microbubbles perform linear oscillations, and the frequency of the backscattered ultrasound is equal to that of the transmitted ultrasound. When the acoustic pressure is raised to hundreds of kilopascals, the oscillations of individual microbubbles are not typically sinusoidal. This results in the generation of nonlinear harmonic ultrasound waves in multiples of the transmitted fundamental frequency (e.g., half the fundamental frequency [subharmonics], twofold the fundamental frequency [second harmonics], threefold the fundamental frequency [third harmonics], etc). ${ }^{(34)}$ Since these harmonic waves normally differ from those reflected from tissues (except subharmonics), they are regarded as the signature of microbubbles. Their intensities are highest when the microbubbles are resonating with the transmitted ultrasound, where the changes in backscattering cross section are the most significant. The resonance of microbubbles is a size-dependent effect. ${ }^{(34)}$ For example, the resonance frequencies of microbubbles that we fabricated were about $10-40$ $\mathrm{MHz}$ and those of the aforementioned commercial product were about 2-10 MHz. ${ }^{(34-36)}$ Note that in these cases, the microbubbles oscillate readily and coherently with the incident ultrasound pulses. This process is generally referred to as stable cavitation.

Further increasing the acoustic pressure may result in the oscillation of microbubbles and transmitted ultrasound waves to the point where they become incoherent. In this case, each microbubble
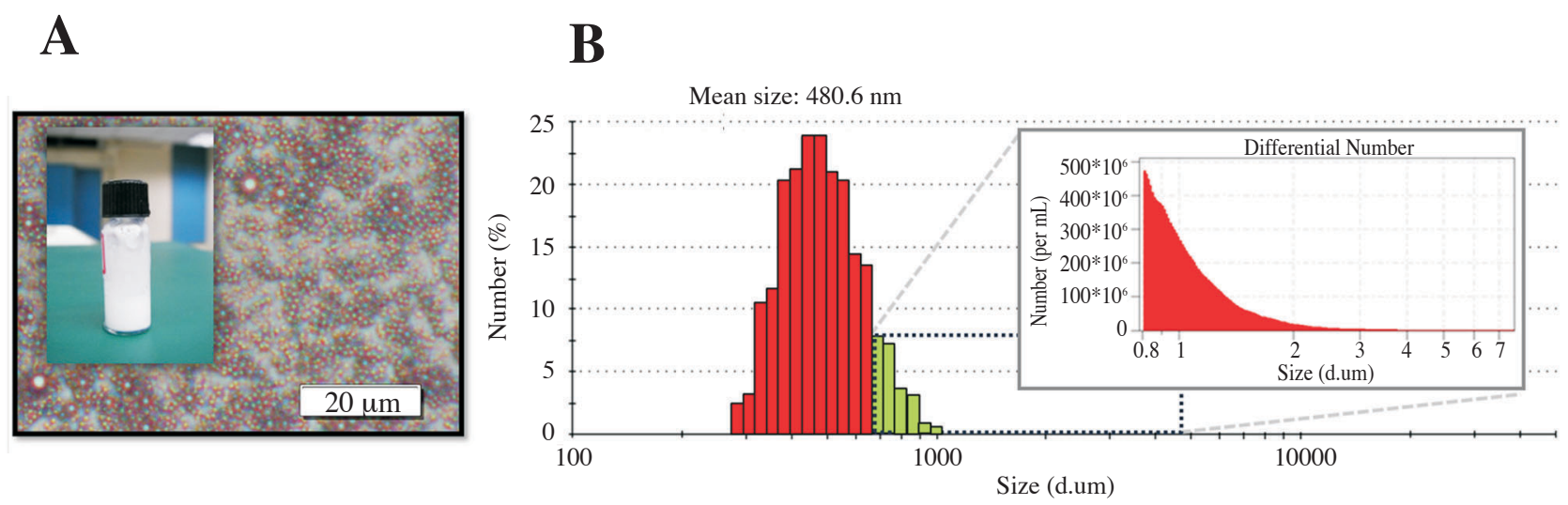

Fig. 1 (A) Bright-field microscopic image, and (B) Size and distribution of homemade microbubbles. 
expands and contracts unstably for a few cycles and ultimately collapses within a very short time. When this occurs in a free field, shock waves can be generated and give rise to microstreaming. When near a wall, the collapse of each microbubble becomes asymmetrical, creating a liquid jet striking the wall. ${ }^{(37,38)}$ Both phenomena are referred to as inertial cavitation. When exposed to ultrasound of appropriate frequency and sufficient pressure, microbubbles may immediately be fragmented into small pieces in the order of nanometers, and the encapsulated gas entirely dissolves in the surrounding medium. ${ }^{(39)}$ This process is referred to as the destruction of the microbubbles, which may cause microstreaming or liquid jets at energy levels even higher than inertial cavitation. ${ }^{(40)}$ Note that both inertial cavitation and microbubble destruction including stable cavitation can cause mechanical stress to tissues in vivo. ${ }^{(41)}$ Many studies suggest the mechanical stress can alter the permeability of the blood vessel and cell membrane to increase drug extravasation, which is introduced in later sections.

\section{Linear contrast-enhanced ultrasound (CEUS) imaging}

The strategies for contrast imaging are currently based on either the linear or nonlinear properties of microbubbles. The linear scheme simply utilizes the echo enhancement of microbubbles. One example is from our pervious study of a colon cancer model in a $\mathrm{BALB} / \mathrm{c}$ mouse. The imaging was conducted using a homemade ultrasound imaging system with a singleelement $25-\mathrm{MHz}$ focused transducer. ${ }^{(42)}$ After the administration of microbubbles, the contrast of tumor tissue was clearly enhanced for up to $6 \mathrm{~min}$, as shown in Fig. 2A-F. Owing to the entrances and exits of circulating microbubbles to the imaging plane, the regional brightness varied over a period of time. These variations served as the signature of the microbubbles, and they were extracted using a highpass filter for interframe filtering. The obtained information was demonstrated as a color-coded overlay on a colocalized B-mode image, as shown in Fig. $2 \mathrm{G}$, which clearly showed the distribution of the tumor microcirculation. The color pixel values were proportional to the microvascular blood flow volume and velocity. Further, a destruction-replenishment technique can be used to accurately assess the flow velocity of the microcirculation. In this technique, a destructive ultrasound pulse was first used to destroy most of the microbubbles in the region of interest. Blood flow velocity can be measured based on the refill rate of microbubbles indicated by the recovery of contrast enhancement. The concept of this technique was first described by Wei et al. in 1998 for use in echocardiology. ${ }^{(43)}$ An adaptation has been made by our group to improve the sensitivity of this technique for use in microperfusion. ${ }^{(44,45)}$

\section{Nonlinear CEUS imaging (microbubble-specific contrast imaging)}

The performance of conventional CEUS imaging can deteriorate with low bubble concentration, tissue motion, and slow perfusion. Several studies have shown the utilization of microbubble nonlinear emissions in microbubble-specific contrast imaging. ${ }^{(46,47)}$ The second harmonics are not used because of interference from tissues at the same frequency. ${ }^{(48)}$ However, inducing the resonance of microbubbles requires the application of sufficiently long ultrasound pulses. Since the resonance frequencies of commercial agents are $2-10 \mathrm{MHz}$, imaging at a half of these frequencies with long pulses can lead to low spatial resolution. To overcome this limitation, a phase inversion technique that utilizes the sum of a pair of images obtained from 2 inverted short ultrasound pulses was proposed. ${ }^{(49)}$ The oscillation of microbubbles results in nonlinear distortion of reflected echoes that cannot be clearly cancelled in paired images, thereby leaving the signature of microbubbles in the summed image. Nonetheless, this technique has to be operated at half the maximum frame rate, and its performance may still be susceptible to movement. Our group has demonstrated two techniques to perform nonlinear contrast imaging with improved spatial resolution. One is amplitude modulation chirp imaging, which utilizes 2 different ultrasound pulses transmitted from separate ultrasound transducers. ${ }^{(50)} \mathrm{A}$ low-frequency pumping pulse is transmitted to induce resonance of the microbubbles. A high-frequency chirp pulse for imaging is then transmitted to simultaneously act on the same group of microbubbles. Periodic changes in the backscattering cross sections of the microbubbles in response to the pumping pulse can modulate the amplitude of the backscattered echoes of the chirp pulse, producing modulated components in the frequency spectrum, as shown in Fig. 3A-D. After 
(A) Pre $\mathrm{MB}_{\mathrm{N}}$

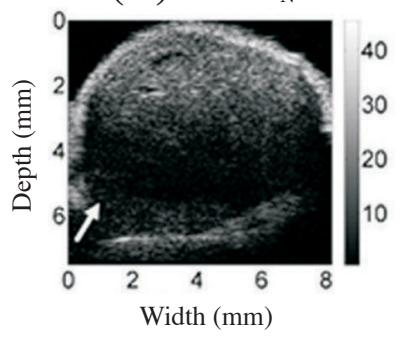

(D) Post 4 min

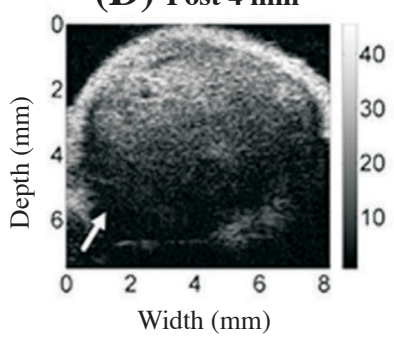

(B) Post 1 min

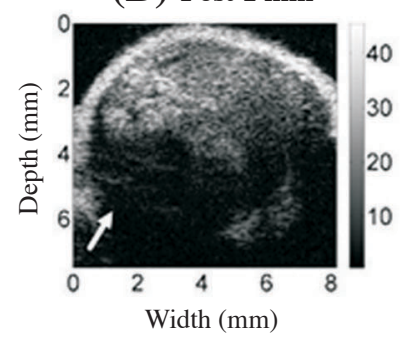

(E) Post 5 min

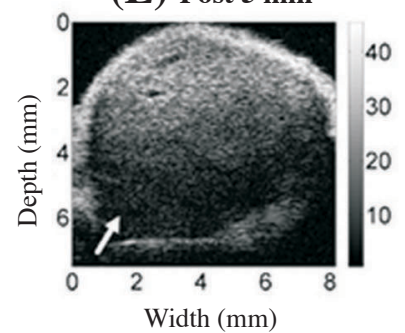

(C) Post 2 min

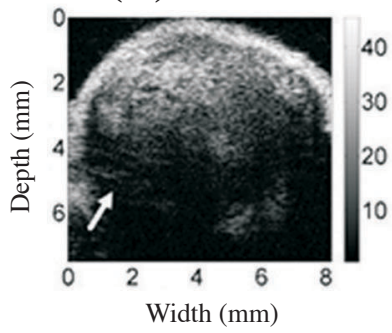

(F) Post 6 min

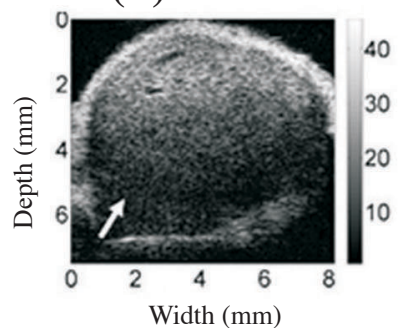

(G)

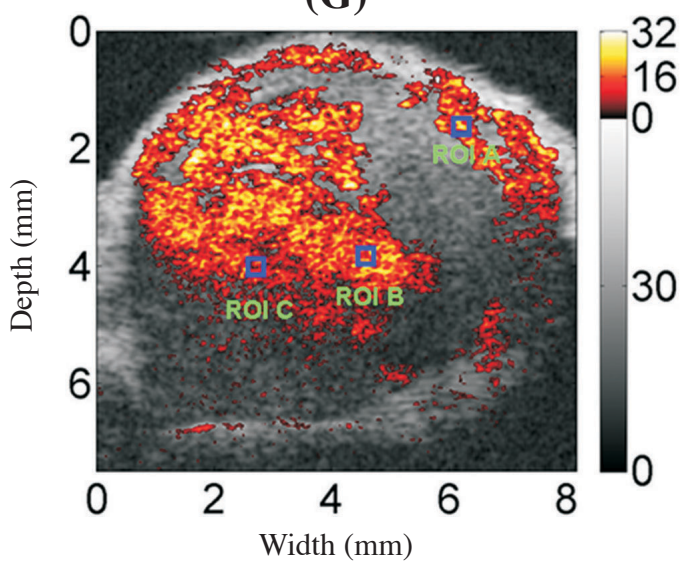

Fig. 2 (A)-(F) B-mode images of a mouse colon tumor for $6 \mathrm{~min}$ after the injection of homemade microbubbles. (G) Contrast image of circulating microbubbles obtained by a high-pass filter for interframe filtering overlaid on a colocalized B-mode image. extracting the derived signal components and applying pulse compression, the contrast of microbubbles can be differentiated from that of tissues in a high spatial resolution. The performance was evaluated by imaging a mouse tail vein, as shown in Fig. 3E. The other nonlinear imaging technique is a dual-frequency (DF) chirp imaging, which utilizes a unique ultrasound pulse that integrates DF difference excitation and chirp excitation techniques. ${ }^{(51)}$ Our previous studies have shown that the DF difference excitation efficiently induces a low-frequency driving force to resonate microbubbles by using high-frequency ultrasound. ${ }^{(52,53)}$ High lateral resolution can be achieved by high-frequency carriers, and axial resolution can be improved after applying pulse compression. Our pre- vious study also showed that DF difference excitation can improve the ability of high-frequency ultrasound to destroy microbubbles, which may be beneficial in the applications of commercial microbubbles in a high-frequency ultrasound system. ${ }^{(54,55)}$ In the future, we aim to incorporate these 2 imaging strategies into clinical ultrasound systems.

\section{Therapeutic usefulness of microbubble cavita- tion}

The therapeutic usefulness of microbubbles has gained much attention in recent years. Both inertial cavitation and destruction of microbubbles are capable of producing strong mechanical stress to enhance the permeability of the surrounding tissues and fur- 
(A)

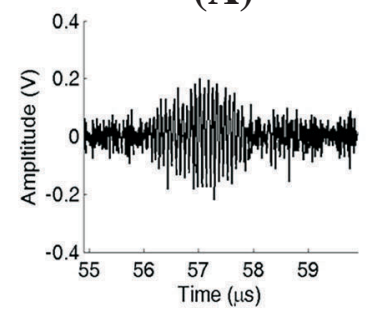

(C)

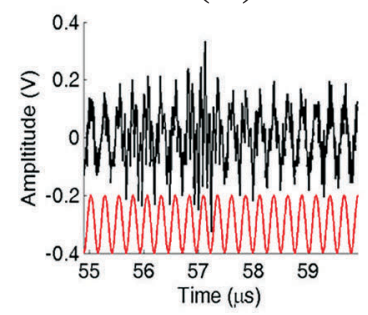

(B)

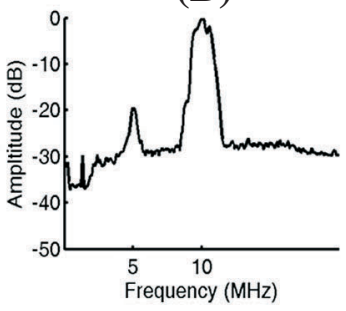

(D)

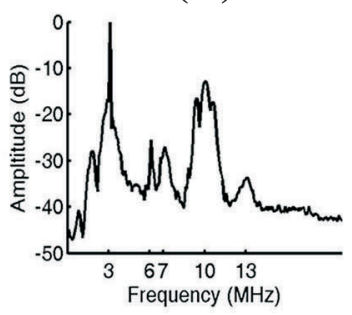

(E)

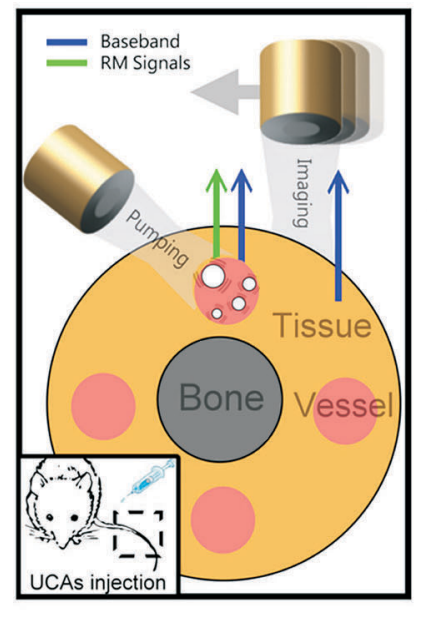

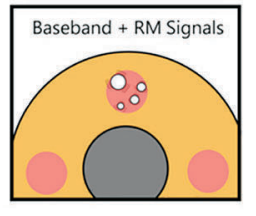

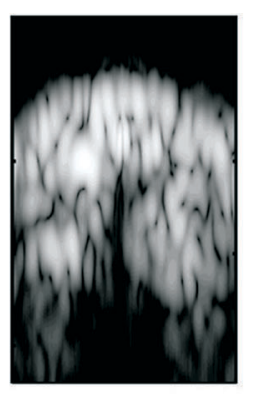

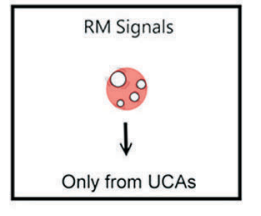

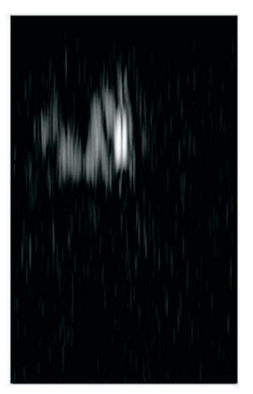

Fig. 3 Waveforms and frequency spectra of the backscattered echoes of chirp pulses, (A) and (B) before, and (C) and (D) after amplitude modulation by a pumping pulse acting on the same group of microbubbles. (E) Contrast image of circulating microbubbles in a mouse tail vein obtained by extracting the derived signal components and applying pulse compression.

ther increase the extravasation of drugs into the cytoplasm or interstitium, as illustrated in Fig. 4A. This may involve several mechanisms. High-energy microstreaming and liquid jets arising from the collapse of microbubbles can locally produce transient holes for direct passage of drugs. ${ }^{(41)}$ They may also cause a transient increase in temperature (reportedly up to $5000 \mathrm{~K}$ ) to alter the fluidity of the cell membrane. ${ }^{(56)}$ Local deposition of such high energy may result in the production of free radicals, which probably cause cell damage that enhances the permeability of endothelial cell layers. ${ }^{(57)}$ In vivo applications have focused, for instance, on disrupting the blood-brain barrier (BBB), a layer of tightly-packed endothelial cells surrounding all capillaries in the brain. ${ }^{(58)}$ Many groups have reported the use of commercial microbubbles with low-frequency ultrasound $(0.4-5$ $\mathrm{MHz}$ ) to increase the permeability of the BBB, allowing the therapeutic or diagnostic agents to leak into the affected regions. ${ }^{(59-61)}$ The opening can be temporary and recoverable, and does not damage the neural cells. ${ }^{(62,63)}$ However, microbubbles exposed to low-frequency ultrasound have been shown to cause rupture of microvessels with extravasation of red blood cells, even at a pressure under the FDA regulatory limit for diagnostic ultrasound equipment. ${ }^{(64)}$
The clinical safety of BBB disruption with low-frequency ultrasound still carries great concern about the risk of intracerebral hemorrhage. ${ }^{(65)}$

Given that concern, our group has developed a high-frequency-based technique (>10 MHz) to disrupt the BBB by using stable cavitation of microbubbles. It has been shown that stable cavitation may also mildly increase the tissue permeability by induced acoustic streaming. ${ }^{(41)}$ A noteworthy advance that we have made in this technique was the use of homemade microbubbles that resonate at $>10 \mathrm{MHz}$. Sprague-Dawley rats were used in these experiments. The presence of BBB disruption was evaluated by the extravasation of a model drug, Evans blue, into the brain tissue; the results are demonstrated in Fig. 4B-D. Stable cavitation at a high frequency enhanced by the resonance of small microbubbles was able to produce effective BBB disruption, which was comparable to that with the low-frequency technique but without any damage even at pressures of up to $2.5 \mathrm{MPa}$. Interestingly, the amount of drug extravasation was found to highly correlate with the enhancement of subharmonic emission (i.e., the signature of stable cavitation of microbubbles), as shown in Fig. 4E. Remarkable safety with the possibility of monitoring the extent of BBB disruption in 


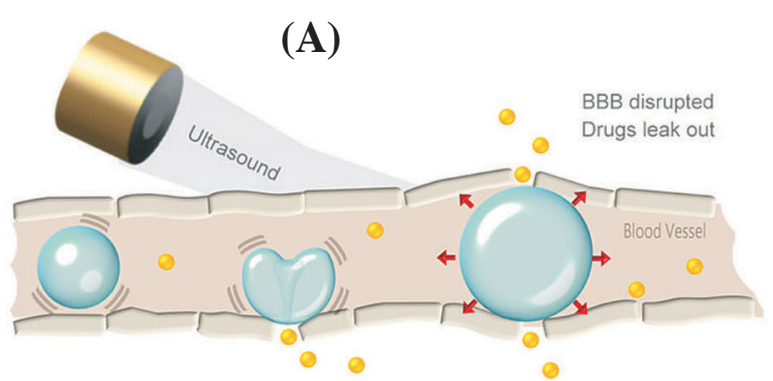

(D)

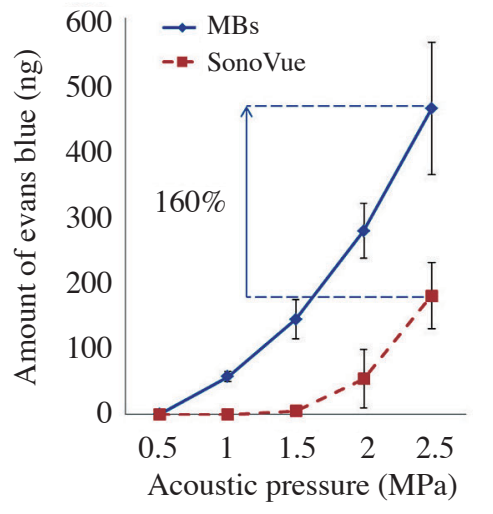

(B)

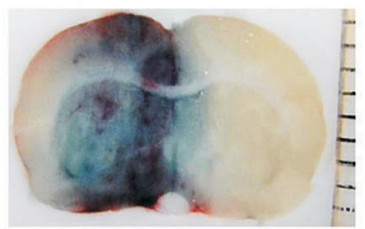

SonoVue ${ }^{\mathrm{TM}}$ with 1-MHz US
(C)

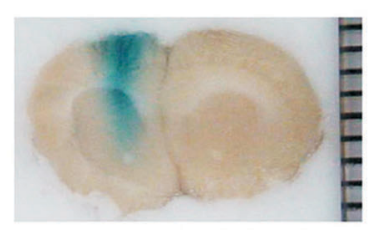

MBs with 10-MHz US
(E)

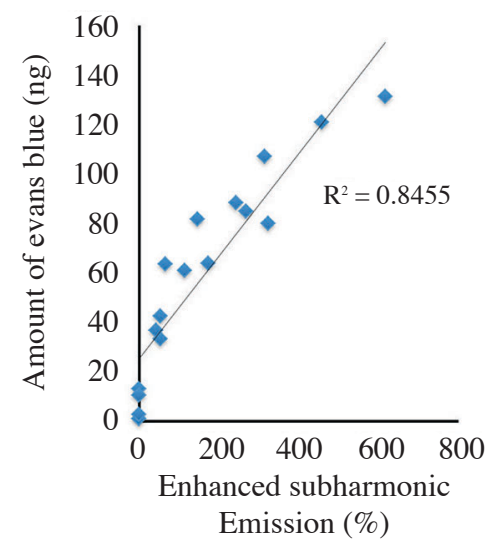

Fig. 4 (A) Illustration of vascular permeabilization by inertial cavitation of microbubbles. Sections of rat brains treated by (B) 1$\mathrm{MHz}$ ultrasound pulses with SonoVue ${ }^{\mathrm{TM}}$ and (C) $10-\mathrm{MHz}$ ultrasound pulses with homemade microbubbles. (D) Leakage of Evans blue in the rat brain treated by the same 10$\mathrm{MHz}$ ultrasound pulses but at different acoustic pressures after the injection of SonoVue ${ }^{\mathrm{TM}}$ (dash) and homemade microbubbles (solid). (E) Leakage of Evans blue in the rat brain as a function of the enhancement of subharmonic emission.

real time suggests this technique has great promise in clinical use.

\section{Drug-loaded microbubbles and ultrasound-con- trolled release}

Microbubbles have been proposed as a new vehicle for carrying drugs and genes. Lipophilic chemotherapeutic drugs such as doxorubicin, paclitaxel, and docetaxel can be incorporated into the lipid layer of microbubbles. ${ }^{(66-68)}$ It has been shown that the in vivo toxicity of paclitaxel-loaded microbubbles is about tenfold lower than that of unencapsulated paclitaxel. ${ }^{(69)}$ To increase the loading capacity, oil that dissolves lipophilic drugs can be introduced into the microbubbles. ${ }^{(70-72)}$ Drug-loaded particles such as micelles or liposomes can be conjugated to the surface of microbubbles using ligand-receptor interaction. ${ }^{(73)}$ Genetic materials (e.g., plasmid DNA) can be electrostatically attached to the surface of positively charged microbubbles that bear cationic lipids. ${ }^{(74)}$ Unlike liposomes, drugloaded microbubbles are acoustically active and are able to exhibit stable or inertial cavitation in response to ultrasound. The payload of drugs or DNA can be locally released by the destruction of microbubbles within the ultrasound-treated region, with a simultaneous increase in the permeability of the tissues. This suggests the potential of microbubble technology in aiding drug or gene therapy, with reduced side effects to normal tissues.

Our group has developed the loading of microbubbles with 1,3-bis (2-chloroethyl)-1nitrosourea (BCNU), a chemotherapeutic agent commonly used in the treatment of brain tumors. ${ }^{(75)}$ The loading efficiency achieved was $75 \%$, as shown in Fig. 5A. Sprague-Dawley rats were used to test the delivery of BCNU by these microbubbles into brain tissues. The deposition of BCNU in the left hemispheres treated by ultrasound increased with the number of sonication sites, and was higher than that in the right hemispheres which had no ultrasound treatment, as shown in Fig. 5B. This indicates that the destruction of BCNU-loaded microbubbles released the BCNU payload and simultaneously induced the disruption of the BBB for passage of $\mathrm{BCNU}$ into the brain tissues. The therapeutic effica- 
cy of delivered BCNU was further validated on a rat brain glioma model. The results of MRI monitoring show that the tumor volume on day 13 had reduced to $37 \%$ of its original volume on day 6 , as shown in Fig. 5C.

\section{Ultrasound targeted contrast agents and imag- ing}

Over the past decade, the development of biomolecular science has extended traditional morphology and perfusion imaging to functional imaging in the assessment of the presence and extent of diseases at a molecular scale. Ultrasound targeted imaging relies on microbubble contrast agents conjugated with targeting ligands that specifically bind to the molecular signatures of diseases or physiological systems. Various ligands, typically antibodies and peptides, have been conjugated to the surface of microbubbles. ${ }^{(76)}$ Site-specific accumulation of image contrast from targeted microbubbles provides great opportunities to noninvasively visualize physiology or pathology that is difficult to distinguish simply based on conventional morphological information. Preclinical applications have been reported in the assessment of atherosclerosis by the expression of intercellular adhesion molecule-1, and vascular thrombi by the expression of glycoprotein IIb/IIIa receptors. ${ }^{(77,78)}$ The extent of tissue inflammation can also be evaluated after incorporating phosphatidylserine lipids into microbubbles to attach to leukocytes. ${ }^{(79)}$ Note that the conjugation can be conducted by either noncovalent linkage, such as biotin-avidin interaction, or covalent linkage, such as maleimide-thiol tethering. Although the biotin-avidin interaction has been extensively used in preclinical studies, the covalent linkage is generally preferable in clinical settings because it is more stable and has lower immunogenicity. ${ }^{(76)}$

Our group demonstrated a simple way to conjugate a new class of targeting ligand, aptamers, to the surface of microbubbles via maleimide-thiol conjugation, as illustrated in Fig. 6A. ${ }^{(28)}$ Aptamers are RNA- or DNA-based targeting ligands fabricated by a process of systematic evolution of ligands by expo-

\section{A}

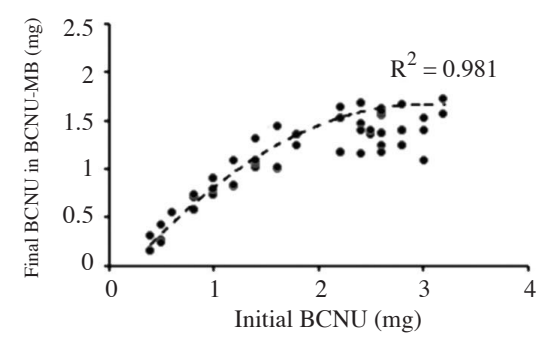

B

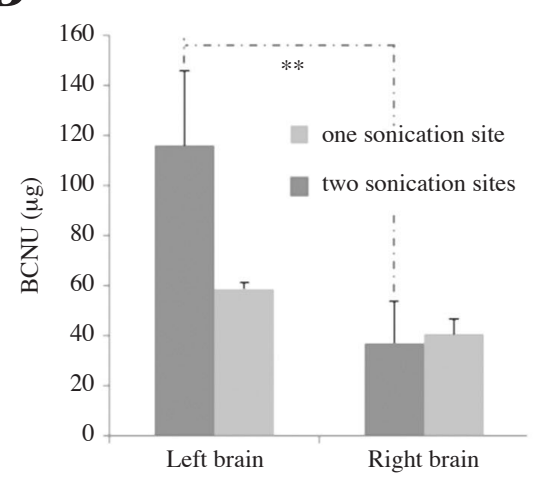

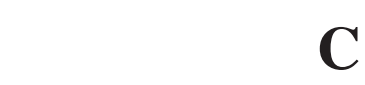
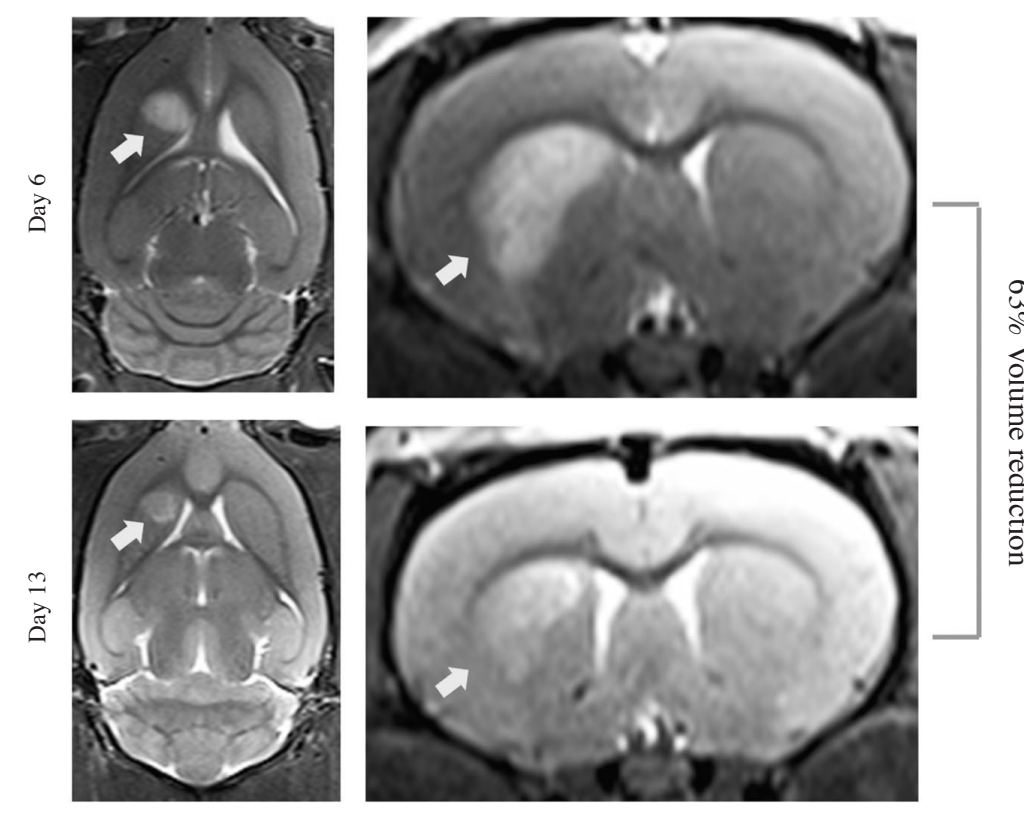

Fig. 5 (A) Amount of encapsulated 1,3-bis (2-chloroethyl)-1-nitrosourea (BCNU) in the microbubbles as a function of the amount of added BCNU. (B) Leakage of BCNU into the treated left and nontreated right hemispheres for 1 and 2 sonication sites. (C) Magnetic resonance images of a rat glioma model on day 6 and day 13 after regular treatment with BCNU-loaded microbubbles and ultrasound treatments. 
nential enrichment. ${ }^{(80)}$ They are biologically stable, less immunogenic, and have low manufacturing costs, but have comparable or even greater binding affinity and specificity than protein-based antibodies. The methods that we proposed are capable of completing the conjugation prior to the formation of microbubbles. Fewer steps will be required in clinical settings. The sgc8c aptamer (50-thiol-ATC TAA CTG CTG CGC CGC CGG GAA AAT ACT GTA CGG TTA GA) was used for the specific targeting of CCRF-CEM cells (CCL-119 T-cell, human acute lymphoblastic leukemia). A flexible polyethylene glycol spacer was designed between each aptamer and the surface of the microbubble to maximize interaction between each aptamer and receptors. The in vitro results show that the aptamer-conjugated microbubbles firmly bound to the surface of the CEM cells, and provided a great echo enhancement of up to $40 \mathrm{~dB}$ in the ultrasound image in comparison with the control, as shown in Fig. 6B-E.

In another in vivo study, we conjugated vascular endothelial growth factor receptor 2 (VEGFR2) antibodies onto microbubbles to assess tumor angiogenesis. After administration into a mouse with a colon tumor, the microbubbles gradually accumulated in the tumor site during the wash-in and wash-out phas- es of circulating microbubbles, as illustrated in Fig. 7A. After the clearance of the circulating microbubbles, the remaining contrast enhancement could mostly be attributed to the adherent microbubbles. The extent of tumor angiogenesis correlating to the expression of VEGFR2 was visualized by subtracting the images before and after microbubble accumulation, as shown in Fig. 7B. For comparison, no accumulation was found for normal microbubbles in the control test, as shown in Fig. 7C. The immunostained section of the tumor for DAPI (blue) and CD31 (red) in Fig. 7D and E, respectively, proved that the accumulation of microbubbles (green) was near the tumor boundary where angiogenesis was significant.

\section{Challenges and limitations}

As described earlier, microbubbles are able to carry drugs or genes, and locally release the payload by applying ultrasound in the intended regions. The targeting ability of bioconjugated microbubbles opens the door for targeted therapy. Combined with the aforementioned microbubble technology, microbubbles can serve as a multifunction platform that is not only useful in diagnoses but also in therapies, permitting simultaneous imaging and localiza-
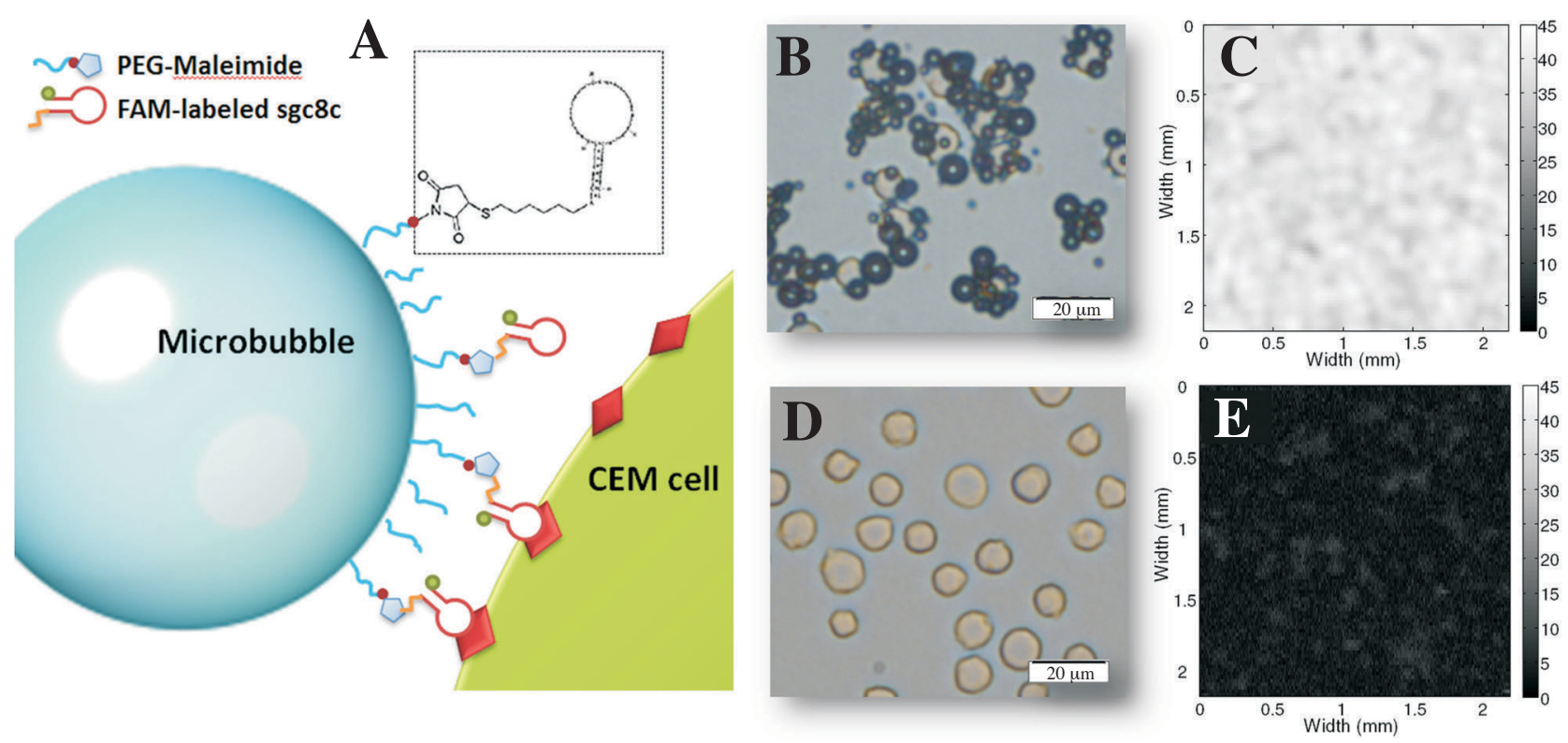

Fig. 6 (A) Scheme of an aptamer-conjugated microbubble binding to a CEM cell. (D) Bright-field microscopic images and ultrasound C-mode scanning images of CEM cells treated by (B) and (C) the aptamer-conjugated microbubbles, and (D) and (E) normal microbubbles. 

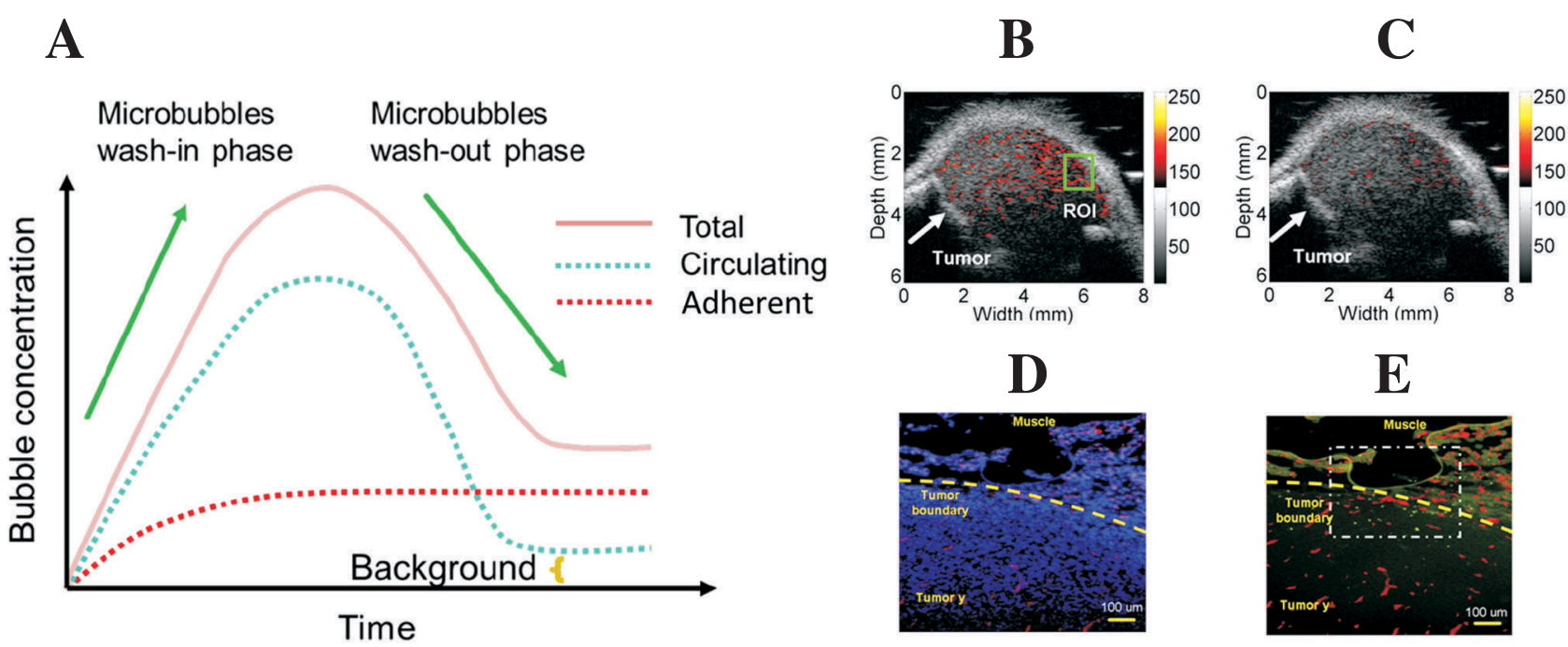

Fig. 7 (A) Scheme of the concentration of adherent and circulating microbubbles during the wash-in and wash-out phases of vascular endothelial growth factor receptor 2-targeted microbubbles. (B) Contrast image obtained by subtracting images before and after microbubble accumulation and overlaid on a colocalized B-mode image. (C) Control of (B) using normal microbubbles. (D), (E) Fluorescence microscopic images of an immunostained tumor section for DAPI (blue), CD31 (red), and adherent microbubbles (green).

tion of the therapy. However, there are still some challenges in targeted and drug-loaded microbubbles that must be overcome before they are approved for clinical use. The adhesion efficiency of targeted microbubbles might be low under certain physiological flow conditions. ${ }^{(81)}$ Although the microbubbles fabricated in our studies can exist in vivo for up to 20 min, some situations may require them to remain in vivo for several hours or more than one day to attain an accumulated contrast or therapeutic effect. The challenges may be overcome by acoustic radiation force, which has been demonstrated to accelerate the adhesion and accumulation of targeted microbubbles. ${ }^{\left({ }^{82}\right)}$ The mechanism is to drive these microbubbles toward the vessel wall by using lowenergy ultrasound without causing microbubble disruption. Another method is the use of polymershelled microbubbles, which are acoustically active in vivo for several hours. ${ }^{(83)}$

Our group is currently developing the precursors of microbubbles-phase-change droplets-as ultrasound contrast agents. These droplets are originally in the liquid phase but can be vaporized into gaseous microbubbles upon ultrasound excitation. ${ }^{(84)}$ Droplets are much more stable in vivo for more than 1 day, and carry a larger drug payload than conventional microbubbles. ${ }^{(85)}$ Nanoscale agents are much easier to fabricate in the liquid phase than in the gaseous phase. The small size might allow the droplets to extravasate from the blood vessel to interact with receptors that may be present within tissues, and may enable passive targeting in tumors via an enhanced permeability and retention effect. ${ }^{(86)}$ Research is underway to study whether the microbubbles derived from phase-change droplets can also be applied in the aforementioned microbubble technology.

\section{Conclusions}

In this article, we reviewed current developments in microbubble technology, and efforts by our laboratory in emerging diagnostic and therapeutic applications of microbubbles. Microbubbles were originally designed as UCAs to improve the sensitivity of conventional ultrasound imaging. The uniqueness of microbubbles, including bioconjugation, drug encapsulation, cavitation, and nonlinear emission, allow them to be used simultaneously as diagnostic and therapeutic agents. Applications include microbubble-specific imaging, ultrasound-aided drug delivery, and targeted imaging and therapy. Our group has developed two techniques of microbubblespecific imaging with high spatial resolution. Our 
group has also developed lipid-based microbubbles with a drug payload (e.g., BCNU) and targeting ligands (e.g., VEGFR2 antibodies). In vivo studies showed the visualization of tumor angiogenesis in a mouse colon tumor by VEGFR2-targeted microbubbles, and the therapeutic effect of ultrasound-aided BCNU delivery to a rat brain tumor. Stable cavitation at high frequency enhanced by the resonance of small microbubbles seems to be a very safe modality for enhancing tissue permeability. These applications are promising but require further improvement for clinical use.

\section{Acknowledgements}

The authors acknowledge the National Science Council of Taiwan for grant support (NSC 98-2320B-007-002-MY3 and 99-2218-E-182-002), and our laboratory staff, Jia-Jiun Chen, Chung-Hsin Wang, Ching-Hsiang Fan, Ting-Yu Huang, and Chien-Yu Ting, for their efforts in the experiments and preparation of the figures.

\section{REFERENCES}

1. Jang IK, Bouma BE, Kang DH, Park SJ, Park SW, Seung KB, Choi KB, Shishkov M, Schlendorf K, Pomerantsev E, Houser SL, Aretz HT, Tearney GJ. Visualization of coronary atherosclerotic plaques in patients using optical coherence tomography: comparison with intravascular ultrasound. J Am Coll Cardiol 2002;39:604-9.

2. Joyner CR, Reid JM. Applications of ultrasound in cardiology and cardiovascular physiology. Prog Cardiovasc Dis 1963;5:482-97.

3. Chen JJ, Chen JJ, Chiang CS, Hong JH, Yeh CK. Assessment of tumor vasculature for diagnostic and therapeutic applications in a mouse model in vivo using 25MHz power Doppler imaging. Ultrasonics 2011;51:92531.

4. Yeh CK, Chen JJ, Li ML, Luh JJ, Chen JJ. In vivo imaging of blood flow in the mouse Achilles tendon using high-frequency ultrasound. Ultrasonics 2009;49:226-30.

5. Liao YY, Tsui PH, Li CH, Chang KJ, Kuo WH, Chang $\mathrm{CC}$, Yeh CK. Classification of scattering media within benign and malignant breast tumors based on ultrasound texture-feature-based and Nakagami-parameter images. Med Phys 2011;38:2198-207.

6. Schor AM, Schor SL. Tumour angiogenesis. J Pathol 1983;141:385-413.

7. Folkman J. New perspectives in clinical oncology from angiogenesis research. Eur J Cancer 1996;32A:2534-9.

8. Kerbel RS. Tumor angiogenesis: past, present and the near future. Carcinogenesis 2000;21:505-15.

9. Browder T, Butterfield CE, Kräling BM, Shi B, Marshall B, O'Reilly MS, Folkman J. Antiangiogenic scheduling of chemotherapy improves efficacy against experimental drug-resistant cancer. Cancer Res 2000;60:1878-86.

10. Gramiak R, Shah PM. Echocardiography of the aortic root. Invest Radiol 1968;3:356-66.

11. Quaia E. Microbubble ultrasound contrast agents: an update. Eur Radiol 2007;17:1995-2008.

12. Dayton PA, Ferrara KW. Targeted imaging using ultrasound. J Magn Reson Imaging 2002;16:362-77.

13. Foster FS, Burns PN, Simpson DH, Wilson SR, Christopher DA, Goertz DE. Ultrasound for the visualization and quantification of tumor microcirculation. Cancer Metastasis Rev 2000;19:131-8.

14. Cohen JL, Cheirif J, Segar DS, Gillam LD, Gottdiener JS, Hausnerova E, Bruns DE. Improved left ventricular endocardial border delineation and opacification with OPTISON (FS069), a new echocardiographic contrast agent. J Am Coll Cardiol 1998;32:746-52.

15. Keller MW, Feinstein SB, Watson DD. Successful left ventricular opacification following peripheral venous injection of sonicated contrast agent: An experimental evaluation. Am Heart J 1987;114:570-5.

16. Ries F, Honisch C, Lambertz M, Schlief R. A transpulmonary contrast medium enhances the transcranial Doppler signal in humans. Stroke 1993;24:1903-9.

17. Harvey CJ, Blomley MJ, Eckersley RJ, Cosgrove DO, Patel N, Heckemann RA, Butler-Barnes J. Hepatic malignancies: improved detection with pulse-inversion US in late phase of enhancement with SH U 508A-early experience. Radiology 2000;216:903-8.

18. Hauff P, Fritzsch T, Reinhardt M, Weitschies W, Lüders F, Uhlendorf V, Heldmann D. Delineation of experimental liver tumors in rabbits by a new ultrasound contrast agent and stimulated acoustic emission. Invest Radiol 1997;32: 94-9.

19. Quaia E, Calliada F, Bertolotto M, Rossi S, Garioni L, Rosa L, Pozzi-Mucelli R. Characterization of focal liver lesions with contrast-specific US modes and a sulfur hexafluoride-filled microbubble contrast agent: diagnostic performance and confidence. Radiology 2004;232:42030.

20. Arnold JR, Karamitsos TD, Pegg TJ, Francis JM, Olszewski R, Searle N, Senior R, Neubauer S, Becher H, Selvanayagam JB. Adenosine stress myocardial contrast echocardiography for the detection of coronary artery disease: a comparison with coronary angiography and cardiac magnetic resonance. JACC-Cardiovasc Imag 2010;3:934-43.

21. Correas JM, Hélénon O, Moreau JF. Contrast-enhanced ultrasonography of native and transplanted kidney diseases. Eur Radiol 1999;9:S394-400.

22. Eiberg JP, Hansen MA, Jensen F, Rasmussen JB, Schroeder TV. Ultrasound contrast-agent improves imag- 
ing of lower limb occlusive disease. Eur J Vasc Endovasc Surg 2003;25:23-8.

23. Hancock J, Dittrich H, Jewitt DE, Monaghan MJ. Evaluation of myocardial, hepatic, and renal perfusion in a variety of clinical conditions using an intravenous ultrasound contrast agent (Optison) and second harmonic imaging. Heart 1999;81:636-41.

24. SonoVue: EPAR - Product Information. Available from http://www.ema.europa.eu/docs/en_GB/document_library/EPAR _-_Product_Information/human/000303/WC500055380.pdf. Accessed September 2011.

25. Luminity: EPAR - Product Information. Available from http://www.ema.europa.eu/docs/en_GB/document_library/EPAR _-_Product_Information/human/000654/WC500045020.pdf. Accessed September 2011.

26. Optison: EPAR - Product Information. Available from http://www.ema.europa.eu/docs/en_GB/document_library/EPAR _-_Product_Information/human/000166/WC500059461.pdf. Accessed September 2011.

27. Kang ST, Yeh CK. A maleimide-based in-vitro model for ultrasound targeted imaging. Ultrason Sonochem 2011;18:327-33.

28. Wang CH, Huang YF, Yeh CK. Aptamer-conjugated nanobubbles for targeted ultrasound molecular imaging. Langmuir 2011;27:6971-6.

29. Meltzer RS, Glen Tickner E, Popp RL. Why do the lungs clear ultrasonic contrast? Ultrasound Med Biol 1980;6:263-9.

30. Schneider M. Characteristics of SonoVueTM. Echocardiography 1999;16:743-6.

31. Klibanov AL. Targeted delivery of gas-filled microspheres, contrast agents for ultrasound imaging. Adv Drug Deliv Rev 1999;37:139-57.

32. Yanagisawa K, Moriyasu F, Miyahara T, Yuki M, Iijima H. Phagocytosis of ultrasound contrast agent microbubbles by Kupffer cells. Ultrasound Med Biol 2007;33:31825.

33. Morgan KE, Allen JS, Dayton PA, Chomas JE, Klibaov AL, Ferrara KW. Experimental and theoretical evaluation of microbubble behavior: effect of transmitted phase and bubble size. IEEE Trans Ultrason Ferroelectr Freq Control 2000;47:1494-509.

34. Shi WT, Forsberg F. Ultrasonic characterization of the nonlinear properties of contrast microbubbles. Ultrasound Med Biol 2000;26:93-104.

35. Goertz DE, de Jong N, van der Steen AFW. Attenuation and size distribution measurements of Definity and manipulated Definity populations. Ultrasound Med Biol 2007;33:1376-88.

36. van der Meer SM, Versluis M, Lohse D, Chin CT, Bouakaz A, de Jong N. The resonance frequency of sonovue as observed by high-speed optical imaging. Proceedings of IEEE Ultrasonics Symposium 2004;1:3435.

37. Lauterborn W, Hentschel W. Cavitation bubble dynamics studied by high speed photography and holography: part one. Ultrasonics 1985;23:260-8.

38. Lauterborn W, Hentschel W. Cavitation bubble dynamics studied by high speed photography and holography: part two. Ultrasonics 1986;24:59-65.

39. Chomas JE, Dayton PA, May D, Allen J, Klibanov A, Ferrara K. Optical observation of contrast agent destruction. Appl Phys Lett 2000;77:1056.

40. Dijkmans PA, Juffermans LJM, Musters RJP, van Wamel A, ten Cate FJ, van Gilst W, Visser CA, de Jong N, Kamp O. Microbubbles and ultrasound: from diagnosis to therapy. Eur J Echocardiogr 2004;5:245-56.

41. Husseini GA, Diaz de la Rosa MA, Richardson ES, Christensen DA, Pitt WG. The role of cavitation in acoustically activated drug delivery. J Control Release 2005;107:253-61.

42. Yeh CK, Chunh CH, Chen JJ, Chen JJ. High-frequency ultrasonic imaging system: a Preliminary small animals study system. Int J Elec Eng 2008;15:195-202.

43. Wei K, Jayaweera AR, Firoozan S, Linka A, Skyba DM, Kaul S. Quantification of myocardial blood flow with ultrasound-induced destruction of microbubbles administered as a constant venous infusion. Circulation 1998;97:473-83.

44. Yeh CK, Ferrara KW, Kruse DE. High-resolution functional vascular assessment with ultrasound. IEEE Trans Ultrason Ferroelectr Freq Control 2004;23:1263-75.

45. Yeh CK, Lu SY, Chen YS. Microcirculation volumetric flow assessment using high-resolution, contrast-assisted images. IEEE Trans Ultrason Ferroelectr Freq Control 2008;55:74-83.

46. Forsberg F, Shi WT, Goldberg BB. Subharmonic imaging of contrast agents. Ultrasonics 2000;38:93-8.

47. Bouakaz A, Frigstad S, Ten Cate FJ, de Jong N. Super harmonic imaging: a new imaging technique for improved contrast detection. Ultrasound Med Biol 2002;28:59-68.

48. Ziegler L, O'Brien RT. Harmonic ultrasound: a review. Vet Radiol Ultrasound 2002;43:501-9.

49. Burns PN, Wilson SR, Simpson DH. Pulse inversion imaging of liver blood flow: improved method for characterizing focal masses with microbubble contrast. Invest Radiol 2000;35:58-71.

50. Li ML, Kuo YC, Yeh CK. Amplitude-modulation chirp imaging for contrast detection. Ultrasound Med Biol 2010;36:1535-45.

51. Cheng CH, Shen CC, Yeh CK. Dual-frequency chirp imaging for contrast detection. Phys Med Biol 2011;56: 2767-78.

52. Yeh CK, Su SY, Shen CC, Li ML. Dual high-frequency difference excitation for contrast detection. IEEE Trans Ultrason Ferroelectr Freq Control 2008;55:2164-76.

53. Shen CC, Cheng CH, Yeh CK. Phase-dependent dual-frequency contrast imaging at sub-harmonic frequency. IEEE Trans Ultrason Ferroelectr Freq Control 2011;58:379-88.

54. Shen CC, Su SY, Cheng CH, Yeh CK. Dual-high-frequen- 
cy ultrasound excitation on microbubble destruction volume. Ultrasonics 2010;50:698-703.

55. Yeh CK, Su SY, Shen CC. Microbubble destruction by dual-high-frequency ultrasound excitation. IEEE Trans Ultrason Ferroelectr Freq Control 2009;56:1113-8.

56. Holland CK, Apfel RE. An improved theory for the prediction of microcavitation thresholds. IEEE Trans Ultrason Ferroelectr Freq Control 1989;36:204-8.

57. Basta G, Venneri L, Lazzerini G, Pasanisi E, Pianelli M, Vesentini N, Del Turco S, Kusmic C, Picano E. In vitro modulation of intracellular oxidative stress of endothelial cells by diagnostic cardiac ultrasound. Cardiovasc Res 2003;58:156-61.

58. Rubin LL, Staddon JM. The cell biology of the bloodbrain barrier. Annu Rev Neurosci 1999;22:11-28.

59. Kinoshita M, McDannold N, Jolesz FA, Hynynen K. Noninvasive localized delivery of Herceptin to the mouse brain by MRI-guided focused ultrasound-induced bloodbrain barrier disruption. Proc Natl Acad Sci USA 2006;103:11719-23.

60. Liu HL, Hua MY, Chen PY, Chu PC, Pan CH, Yang HW, Huang CY, Wang JJ, Yen TC, Wei KC. Blood-brain barrier disruption with focused ultrasound enhances delivery of chemotherapeutic drugs for glioblastoma treatment. Radiology 2010;255:415-25.

61. McDannold N, Vykhodtseva N, Raymond S, Jolesz FA, Hynynen K. MRI-guided targeted blood-brain barrier disruption with focused ultrasound: Histological findings in rabbits. Ultrasound Med Biol 2005;31:1527-37.

62. Hynynen K, McDannold N, Vykhodtseva N, Jolesz FA. Noninvasive MR imaging-guided focal opening of the blood-brain barrier in rabbits. Radiology 2001;220:640-6.

63. Hynynen K, McDannold N, Vykhodtseva N, Jolesz FA. Non-invasive opening of BBB by focused ultrasound. Acta Neurochir Suppl 2003;86:555-8.

64. Skyba DM, Price RJ, Linka AZ, Skalak TC, Kaul S. Direct in vivo visualization of intravascular destruction of microbubbles by ultrasound and its local effects on tissue. Circulation 1998;98:290-3.

65. Reinhard M, Hetzel A, Krüger S, Kretzer S, Talazko J, Ziyeh S, Weber J, Els T. Blood-brain barrier disruption by low-frequency ultrasound. Stroke 2006;37:1546-8.

66. Cochran MC, Eisenbrey J, Ouma RO, Soulen M, Wheatley MA. Doxorubicin and paclitaxel loaded microbubbles for ultrasound triggered drug delivery. Int $\mathrm{J}$ Pharm 2011;414:161-70.

67. Tinkov S, Coester C, Serba S, Geis NA, Katus HA, Winter G, Bekeredjian R. New doxorubicin-loaded phospholipid microbubbles for targeted tumor therapy: in-vivo characterization. J Control Release 2010;148:368-72.

68. Kang J, Wu X, Wang Z, Ran H, Xu C, Wu J, Wang Z, Zhang Y. Antitumor effect of docetaxel-loaded lipid microbubbles combined with ultrasound-targeted microbubble activation on VX2 rabbit liver tumors. J Ultrasound Med 2010;29:61-70.
69. Tartis MS, McCallan J, Lum AFH, LaBell R, Stieger SM, Matsunaga TO, Ferrara KW. Therapeutic effects of paclitaxel-containing ultrasound contrast agents. Ultrasound Med Biol 2006;32:1771-80.

70. Fang JY, Hung CF, Liao MH, Chien CC. A study of the formulation design of acoustically active lipospheres as carriers for drug delivery. Eur J Pharm Biopharm 2007;67:67-75.

71. Lentacker I, Geers B, Demeester J, De Smedt SC, Sanders NN. Design and evaluation of doxorubicin-containing microbubbles for ultrasound-triggered doxorubicin delivery: cytotoxicity and mechanisms involved. Mol Ther 2010;18:101-8.

72. Shortencarier MJ, Dayton PA, Bloch SH, Schumann PA, Matsunaga TO, Ferrara KW. A method for radiation-force localized drug delivery using gas-filled lipospheres. IEEE Trans Ultrason Ferroelectr Freq Control 2004;51:822-31.

73. Lentacker I, De Smedt SC, Demeester J, Van Marck V, Bracke M, Sanders NN. Lipoplex-loaded microbubbles for gene delivery: a trojan horse controlled by ultrasound. Adv Funct Mater 2007;17:1910-6.

74. Chen S, Ding JH, Bekeredjian R, Yang BZ, Shohet RV, Johnston SA, Hohmeier HE, Newgard CB, Grayburn PA. Efficient gene delivery to pancreatic islets with ultrasonic microbubble destruction technology. Proc Natl Acad Sci USA 2006;103:8469-74.

75. Barker M, Hoshino T, Gurcay O, Wilson CB, Nielsen SL, Downie R, Eliason J. Development of an animal brain tumor model and its response to therapy with 1,3-bis(2chloroethyl)-1-nitrosourea. Cancer Res 1973;33:976-86.

76. Lanza GM, Wickline SA. Targeted ultrasonic contrast agents for molecular imaging and therapy. Curr Probl Cardiol 2003;28:625-53.

77. Schumann PA, Christiansen JP, Quigley RM, McCreery TP, Sweitzer RH, Unger EC, Lindner JR, Matsunaga TO. Targeted-microbubble binding selectively to GPIIb IIIa receptors of platelet thrombi. Invest Radiol 2002;37:58793.

78. Villanueva FS, Jankowski RJ, Klibanov S, Pina ML, Alber SM, Watkins SC, Brandenburger GH, Wagner WR. Microbubbles targeted to intercellular adhesion molecule1 bind to activated coronary artery endothelial cells. Circulation 1998;98:1-5.

79. Lindner JR, Song J, Xu F, Klibanov AL, Singbartl K, Ley K, Kaul S. Noninvasive ultrasound imaging of inflammation using microbubbles targeted to activated leukocytes. Circulation 2000;102:2745-50.

80. Nimjee SM, Rusconi CP, Sullenger BA. Aptamers: an emerging class of therapeutics. Annu Rev Med 2005;56: 555-83.

81. Takalkar AM, Klibanov AL, Rychak JJ, Lindner JR, Ley K. Binding and detachment dynamics of microbubbles targeted to P-selectin under controlled shear flow. J Control Release 2004;96:473-82.

82. Dayton P, Klibanov A, Brandenburger G, Ferrara K. 
Acoustic radiation force in vivo: a mechanism to assist targeting of microbubbles. Ultrasound Med Biol 1999;25:1195-201.

83. Lentacker I, De Geest BG, Vandenbroucke RE, Peeters L, Demeester J, De Smedt SC, Sanders NN. Ultrasoundresponsive polymer-coated microbubbles that bind and protect DNA. Langmuir 2006;22:7273-8.

84. Kripfgans OD, Fowlkes JB, Miller DL, Eldevik OP, Carson PL. Acoustic droplet vaporization for therapeutic and diagnostic applications. Ultrasound Med Biol
2000;26:1177-89.

85. Dayton PA, Zhao S, Bloch SH, Schumann P, Penrose K, Matsunaga TO, Zutshi R, Doinikov A, Ferrara KW. Application of ultrasound to selectively localize nanodroplets for targeted imaging and therapy. Mol Imaging 2006;5:160-74.

86. Hashizume H, Baluk P, Morikawa S, McLean JW, Thurston G, Roberge S, Jain RK, McDonald DM. Openings between defective endothelial cells explain tumor vessel leakiness. Am J Pathol 2000;156:1363-80. 


\title{
超音波微氣泡對比劑於診斷及治療之應用
}

\author{
康世聰 葉秩光
}

\begin{abstract}
超音波對比劑 (ultrasound contrast agents) 是一群會產生高度回音的微氣泡 (microbubbles), 可以增加微循環血流在傳統超音波影像上的對比。微氣泡與超音波脈衝達到 共振狀態時會產生特殊的非線性諧波訊號, 此爲微氣泡之特徵因此可用來針對微氣泡進行專 一性的成像 (microbubble-specific imaging)。常微氧泡受到較強超音波脈衝作用產生慣性穴蝕 效應 (inertial cavitation) 或是擊破時會對周邊組織產生機械力, 可提升組織的通透性進而增進 藥物從血液渗漏到組織内或組織間的效率。此外, 利用高頻率超音波所激發的稂定穴蝕效應 (stable cavitation), 一樣可提升組織通透性, 而且在高聲壓時仍不會對組織產生傷害。微氣泡 本身可包覆藥物於其中, 並在超音波誘發微氣泡擊破時將藥物釋放, 這個過程同時也可能提 升組織的通透性, 進而提升藥物進入組織的效率。對微氣泡的表面修飾不同的標靶性分子之 後, 微氣泡就能在不同的生理或病理環境進行累積, 以利標靶性的診斷。本文除了回顧現今 微氧泡技術的發展之外, 也介紹了本團隊針對微氣泡應用於微氣泡専一影像、超音波輔助之 藥物輸送 (ultrasound-aided drug delivery)、標靶影像 (targeted imaging) 等研究的成果。這些應 用的發展都相當具有前景, 但目前仍需進行一些改善才能被臨床應用所接受。(長庚醫誌 2012;35:125-39)
\end{abstract}

關鍵詞：超音波對比劑, 微氣泡, 對比影像, 標靶影像及治療, 超音波藥物釋放, 穴蝕效應 